We therefore suggest that ketamine deserves to be evaluated as an agent which $\frac{\mathrm{D}}{0}$ may prove to be a valuable addition to the therapeutic measures available for the fight to reduce hospital deaths from life threatening asthma.

P. D. TURNPENNY \& S. F. NASH

The Nazareth Hospital,

P. O. Box 11,

16100 Nazareth,

Israel.

\title{
REFERENCES
}

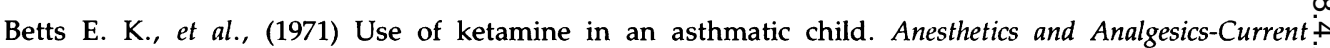
Research 50(30), 420-1.

Bucknall C. E., et al. (1988) Management of asthma in hospital: a prospective audit. British Medical Journal 296, 1637-9.

Burney P. G. J. (1986) Asthma mortality in England and Wales: evidence for a further increase, 1974-84. The Lancet ii, 323-6.

Fisher M. M. (1977) Ketamine hydrochloride in severe bronchospasm. Anaesthesia 32, 771-2.

Jackson R. T., et al. (1982) Mortality from asthma: a new epidemic in New Zealand. British Medical Journal 285, 771-4.

Park G. R. (1987) et al. Ketamine infusion. Anaesthesia 42, 980-3.

Rajanna P., et al. (1982) Ketamine for the relief of bronchospasm during anaesthesia. Anaesthesp 37, 1215.

Robertson C. E., et al. (1985) Use if ether in life threatening severe acute asthma. The Lancet i, 187- 8 .

Rothwell R. P. G., et al. Lessons from the national asthma mortality study: deaths in hospital. The New Zealand Medical Journal 100, 189-200.

Sears MR, et al. Asthma mortality in New Zealand: a two year national study. The New Zealand Medical Journal 98, 271-5.

Sheref SE. (1985) Ketamine and bronchospasm. Anaesthesia 40, 701.

Strube P. J., et al. (1986) Ketamine by continuous infusion in status asthmaticus. Anaesthesia 41, 1017-9. 을

White P. E., et al. Ketamine - its pharmacological and therapeutic uses. Anesthesiology 56, 119-36.

\section{Migration of a Kirschner Wire from the clavicle into the abdominal aorta}

Sir

A 33-year-old male presented to the Accident and Emergency Department on $30 \stackrel{9}{3}$ April, 1987, because of back pain which he claimed was caused by lifting.

The pain was described as constant, discomforting, and mostly in the lower back.

Significant past history included a motor vehicle accident in 1985 during which \% he sustained a fractured right ankle and a fracture of the left clavicle. The fractured $\tilde{N}^{N}$ clavicle was corrected surgically by open reduction and fixation with Kirschner $\omega$ Wires (Fig. 1). Physical examination demonstrated some tenderness in the region of the second lumbar vertebrae and limitation of straight leg raising in both legs. Power, tone, sensation and reflex were normal. 
Plain films of the lumbar spine revealed a metallic density $6.5 \mathrm{~cm}$ long lying centrally and just anterior to the 2 nd and 3rd lumbar vertebrae. (Fig. 2).

Fluoroscopic examination indicated that the metallic body was pulsating. Computerized Tomography indicated that the metallic body was wholly within the lumen of the aorta. (Fig. 3).

X-rays of the clavicle were then reviewed and this revealed that three Kirschner Wires were applied during surgery.

On further discussion the patient stated that he had further surgery eight months after whence two Kirschner Wires were extracted and that the third could not be retrieved. (Fig. 4).

The patients clavicle was then re X-rayed revealing that the Kirschner Wire was broken into 2 fragments and we believe that initially there must have been three fragments. (Fig. 5).

The abdomen was surgically explored and the metallic fragment was extracted through an incision in the aortic wall.

Convalescence was uneventful and the patient was discharged after 5 days.

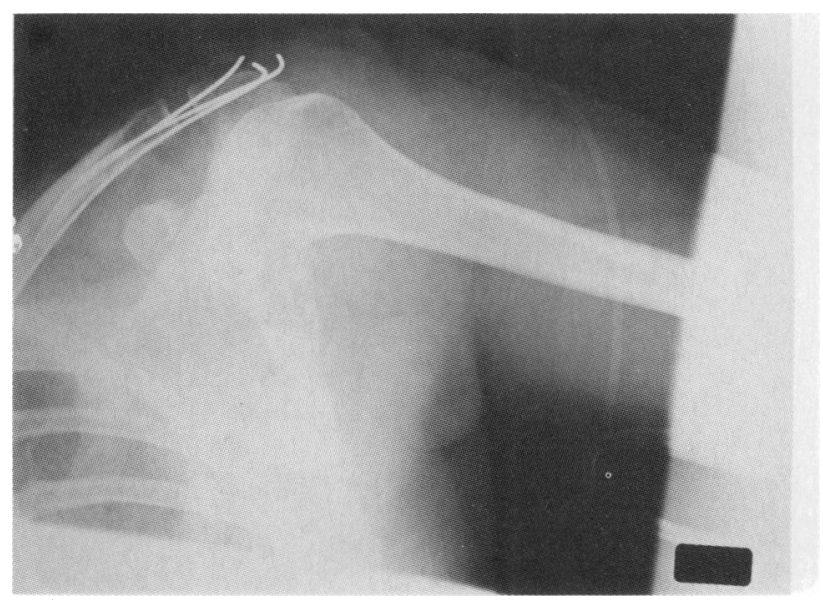

Fig. 1. Fractured clavicle surgically fixed with three Kirschner Wires

Foreign body migration of metallic orthopaedic devices is a well documented occurrence (Mazet, 1943; Leonard \& Gifford, 1965; Norback \& Makula, 1985).

Foreign bodies usually move following localized circumferential osteoporosis whereby its grip on the bone is loosened. Once loose these objects then move either by muscle or gravitational forces and penetrate directly or migrate with the blood stream (Burman et al., 1986). The most probable course of migration in this case was first into the mediastinum and then penetration into the aorta. 


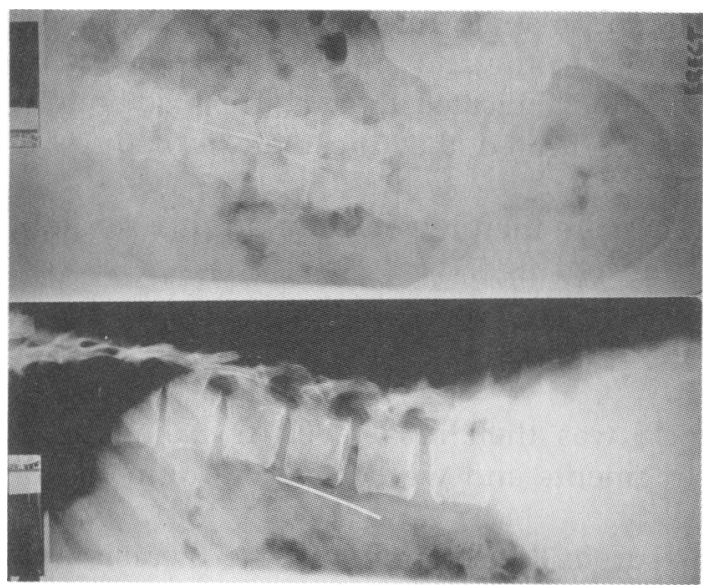

Fig. 2. Metallic density seen lying centrally and just anterior to the 2nd and 3rd lumbar vertebrae

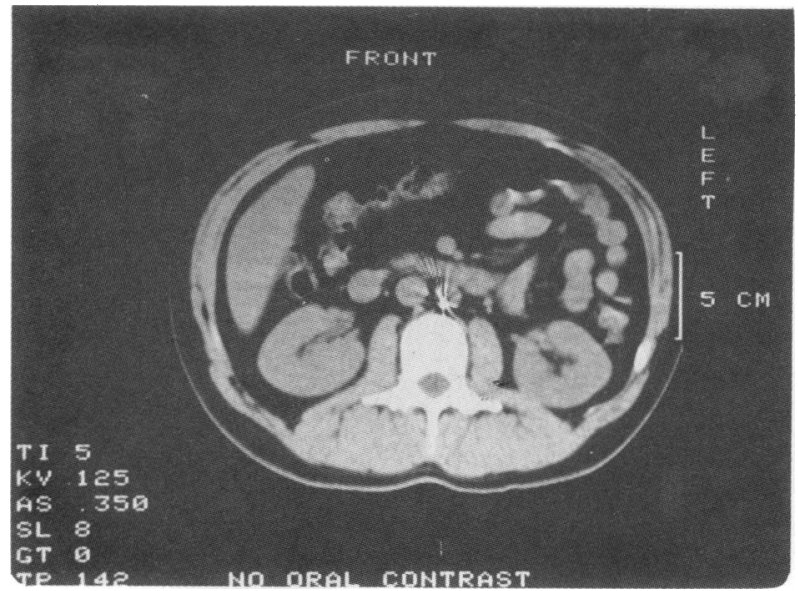

Fig. 3. C.T. Scan showing metallic pin lyning within the lumen of the aorta

All Kirschner Wires should be secured at insertion to prevent migration and if migration does occur, early removal is indicated to prevent potentially serious complications.

P. NAIDOO

Townsville General Hospital

Townsville, U.S.A. 


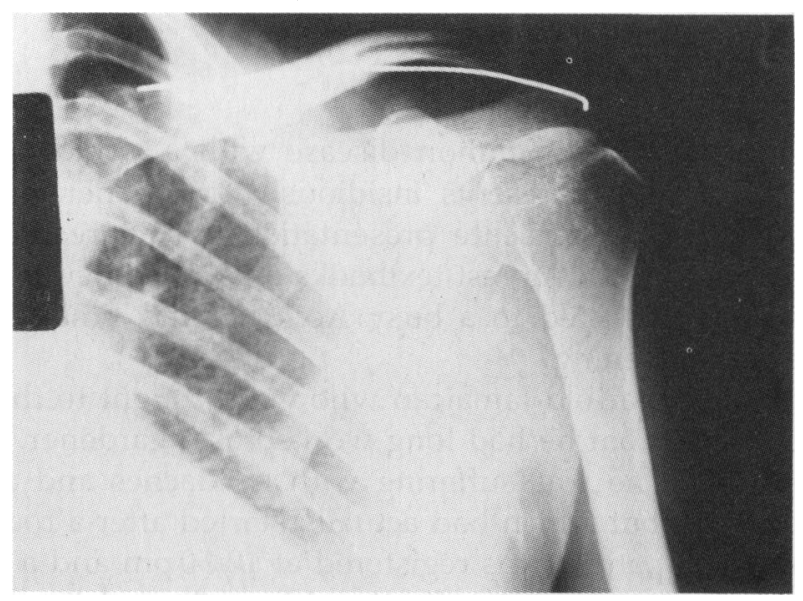

Fig. 4. X-ray showing a Kirschner Wire within the clavicle which could not be retrieved

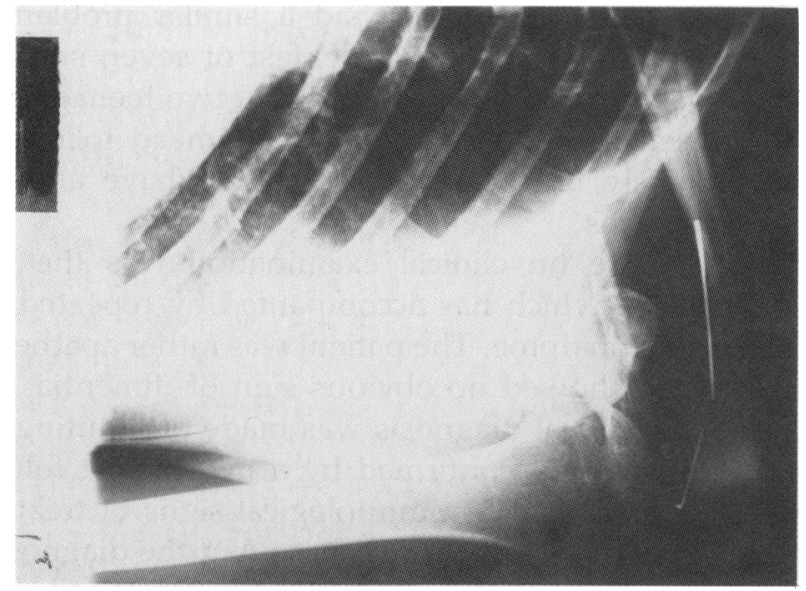

Fig. 5. X-ray showing a fragmented Kirschner Wire

\section{REFERENCES}

Burman M., Crossman S. \& Rosenak S. (1986) The migration of a fracture transfixing pin from the humerus into the mediastinum. American Journal of Roentgenology 76, 1061.

Leonard J. W. \& Gifford R. W. (1965) Migration of Kirschner Wire from the Clavicle into the Pulmonary Artery. Medical Journal of Cardiology 16, 598-600.

Mazet R. J. Jr. (1943) Migration of a Kirschner Wire from shoulder region into the lung. Report of two cases. Bone and Joint Surgery 25, 477.

Nordback I. \& Markkula, H. (1985) Migration of Kirschner wire from Clavicle into ascending aorta. Acta Chiropractica Scandinavica 151, 177-9. 